\title{
Experimental Model of Coccidiosis Caused by Eimeria tenella in Broiler Chickens
}

\author{
Rinat T. Safiullin*, Ekaterina O. Kachanova, Elvira I. Chalysheva and Oleg N. Andreyanov \\ All-Russian Scientific Research Institute of Fundamental and Applied Parasitology of Animals and Plants named after K.I. Skryabin - Branch of the \\ Federal State Budget Scientific Institution «Federal Scientific Center - All-Russian Scientific Research Institute of Experimental Veterenari Medicina \\ K.I. Skryabin and Y.R. Kovalenko the Russian Academy of Sciences», B. Cheremushkinskaya Street 28, 117218 Moscow, Russia. \\ *Corresponding author's E-mail: safiullin_r.t@mail.ru; ORCID: 0000-0003-0450-5527
}

\begin{abstract}
Coccidiosis is the most common protozoan disease in poultry and is often recorded in poultry farms with the freerange system. The share of such poultry farms is constantly growing in Russia. The present study designed an experimental model of coccidiosis induced by Eimeria tenella in broilers. Forty-two 14-days-old broilers of the cross "ABH 47" were divided into seven groups of six broilers each according to the principle of analogs. Broilers were weighed at the beginning and at the end of the experiment. The groups were kept isolated throughout the study. Chickens in groups 1, 2, 3, 4, 5 and 6 were orally infected with E. tenella culture at the doses of 2,000; 1,000; 250; $125 ; 62$ and 15 oocysts $/ \mathrm{ml}$, respectively. Broilers of group 7 were uninfected and served as control. To determine the number of oocysts, all feces from the broilers of each experimental group were daily collected from the days 6 to 12 after infection. Counting was carried out using the McMaster technique. The average number of E. tenella oocysts per gram of feces in broilers of the groups 1 to 6 was 4,080;6,880;1,780;1,530; 662 and 94, respectively. The average daily weight gain in groups 1 to 4 was significantly lower compared to the non-infected control group. The experimental model of coccidiosis in broiler chickens revealed that the number of oocysts excreted with feces is dependent on the dose of infection.
\end{abstract}

Key words: Broilers, Eimeria tenella, Experimental model, Oocysts

\section{INTRODUCTION}

Poultry farms with free-range broilers take a large share in Russia. Coccidian infection is often and largely recorded in such poultry farms (Akbaev et al., 2000; Bakulin, 2006; Kachanova and Safiullin, 2018). It should be remembered that the parent flock can be kept on the floor even in farms where most of the birds are raised in cages (Kirillov, 2008), which may increase the risk of Eimeria infection. In recent years, many European countries, such as Russia undergo a transition to the technology of free-range broiler farming. For heavy hybrids Cobb-500 and Ross-708, free-range farming is preferred. Birds in free-range housing system can move freely throughout the house, which ensures the normal development of organs, particularly the heart, and the organism in general.

Certainly, it is impossible to find a poultry farm free from coccidiosis with free-range cultivation technology (Fisinin, 2008). According to the literature, nine species of Eimeria have been found in the intestines of broilers, of which E. tenella, E. necatris, E. acervulina, E. maxima are most prevalent species (Murzakov and Safiullin, 2012; Safiullin and Murzakov, 2012; Safiullin et al., 2013). The E. tenella is the most pathogenic and common species detected in poultry farms in Europe and Russia (Awais, 2012; Safiullin, 2017; Cha et al., 2018). In many cases, concurrent infections are recorded by several species of Eimeria. The pathogenic effect of Eimeria is caused by massive necrosis of epithelial cells, inflammation of the intestinal wall and consequently, impaired absorption of nutrients from the intestine (Fetter et al., 2013; Safiullin et al., 2016; Prakashbabu et al., 2017). This condition leads to a weakening of the organism and changes in the composition of the intestinal microflora.

For the prevention and treatment of coccidiosis, it is necessary to know the dose of sporulated oocysts which causes infection, duration, and intensity of oocyst shedding in feces of infected poultry. The purpose of the present research was to reproduce an experimental model of coccidiosis induced by E. tenella oocysts in broilers.

\section{MATERIALS AND METHODS}

\section{Ethical approval}

The experiment was carried out in vivarium conditions of the Federal Scientific Center "All-Russian Research and Technological Poultry Institute" of the Russian Academy of Sciences, Sergiev Posad, Russia. The study was randomized, blinded, placebo-controlled and was conducted according to the Guidance for the experimental (preclinical) 
study of new pharmacological substances (Habriev, 2005), the Russian Federation guidelines for good clinical practice (2003) and the rules adopted by European Convention for the protection at vertebrate animals used for experimental and other scientific purposes (ETS 123, 1986).

\section{Preparation of Eimeria tenella oocysts}

The culture of sporulated oocysts of E. tenella (CID Lines, Belgium) was used to infect broilers. The culture contained 2,000 oocysts $/ \mathrm{ml}$. A McMaster chamber was used to count the numbers of sporulated oocysts. The WSH buffer $(17.5 \mathrm{ml}$ of $10 \%$ calcium chloride solution, $5 \mathrm{ml}$ of $10 \%$ magnesium sulfate solution and 3,300 ml of distilled water) with PH 7.1 was prepared and autoclaved for 15 minutes at $120{ }^{\circ} \mathrm{C}$ to dilute culture suspension. The prepared concentrations of E. tenella oocysts were 2,000, 1,000, 250, 125, 62 and 15 oocysts $/ \mathrm{ml}$. A magnetic mixer SH-3 (Company Snablab, Russia) was used to achieve good mixing.

\section{Determination of the percentage of oocysts sporulation}

The percentage of sporulation of oocyst culture was determined using a McMaster counting chamber and a microscope. The percentage of sporulation was derived by dividing the number of sporulated by the total number of counted oocysts. The concentration of oocysts was determined using a McMaster chamber. Briefly, $0.2 \mathrm{ml}$ of the suspension of oocysts and $9.8 \mathrm{ml}$ of a saturated solution of sodium chloride $(40 \%)$ were stirred and transferred into the chamber. After three minutes the oocysts were counted. The volume of one cell is $0.15 \mathrm{ml}$. The number of oocysts was counted in all six cells of the chamber and the arithmetic average was derived. The number of sporulated oocysts in $1 \mathrm{ml}$ of suspension was determined as follows:

Ко $=$ Ок $\times 50 \times 0.95$

Where, Kо is the number of sporulated oocysts in $1 \mathrm{ml}$ of suspension; Ок is the number of detected oocysts; 50 is the dilution rate; 0.95 is the percentage of sporulation.

\section{Broilers}

Forty-two, 14-day-old, broilers cross "ABH 47" were included in the study. Chickens were purchased from the "Zagorsk experimental farm breeding and genetic center", Sergiev Posad, Russia. All broilers were individually weighed and subjected to clinical examination. Broilers were free from Eimeria infection according to the obtained results from coproscopic examination by Darling's method (Krylov, 1996). Chickens were divided into seven groups of six animals each according to the principle of analogs. Each group was kept in an isolated cage. All groups were under similar conditions in hen-houses and had the same diet during the experiment according to zootechnical norms Feed and water were provided ad libitum. The birds were fed crumble diet PK-2 (Ramensky Bakery Company, Russia) during 1-35 days of age (Fisinin et al., 2011). The feed did not contain anti-coccidial agents. The air temperature was $22 \pm 2{ }^{\circ} \mathrm{C}$ and the humidity was $60 \pm 5 \%$. Daily clinical observations of the general conditions, visible physiological changes, the behavior of broiler chickens as well as feed and water intake were recorded throughout the period of the experiment.

\section{Disinfection procedures}

Cleaning and disinfection were carried out in hen-houses before the experiment. Wet disinfection was conducted with $0.5 \%$ Virocid disinfectant (CID LINES, Belgium). Also, the recommended dose of hot sodium hydroxide solution $\left(80^{\circ} \mathrm{C}\right.$ ) was used for disinfection (Rules, 2002). The disinfection mats were weekly refilled in hen-houses.

\section{Experimental infection model}

Fourteen-days-old broiler chickens in six groups were infected with $E$. tenella oocysts. Groups 1, 2, 3, 4, 5 and 6 were orally inoculated with suspensions containing 2,$000 ; 1,000 ; 250 ; 125 ; 62$ and 15 oocysts/ml, respectively. Group 7 as uninfected control received $1 \mathrm{ml}$ of buffer solution.

\section{Fecal collection}

The entire feces were daily collected from each experimental group separately during days 6 to 12 post-infection to determine the presence of oocysts. Then the feces were weighed, water was added to reach a total weight of 2,000 g, and mixed by a mixer for five minutes. Samples for further analysis were taken from each group in an amount of $25 \mathrm{~g}$, placed in plastic disposable containers and kept in $4 \%$ potassium dichromate solution and stored in a refrigerator at $4{ }^{\circ} \mathrm{C}$. The experiments were conducted in laboratory All-Russian Scientific Research Institute of Fundamental and Applied Parasitology of Animals and Plants named after K.I. Skryabin.

\section{Oocysts counting}

The oocysts were counted using the McMaster technique. Briefly, 3-5 $\mathrm{ml}$ of saturated sodium chloride solution (density: $1.18 \mathrm{~g} / \mathrm{cm}^{3}$ ) was added to $1 \mathrm{~g}$ of each fecal sample in a glass cup and stirred with a stick until a homogeneous 
mass. The solution was added to reach a final volume of $30 \mathrm{ml}$. The slurry was passed through a sieve into another tube, the precipitate on the sieve was pressed with a stick. Then $0.15 \mathrm{ml}$ of suspension from the middle part of the tube was transferred quickly into each of the six cells of the chamber, covered with a lid and left for three minutes. During the indicated time, the oocysts adhered to the surface of the chamber grid. The number of oocysts was determined using an optical microscope (eyepiece 10x, objective 10x and 40x; Zeiss Primo Star). The oocysts were counted in six cells of the chamber for each sample and the average number per day was recorded. Since $0.15 \mathrm{ml}$ is $1 / 200 \mathrm{of} 30 \mathrm{ml}$, the average number of oocysts counted in six cells was multiplied by 200 to determine the number of oocysts per gram (OPG) of feces. The number of isolated oocysts from total feces per day for each group calculated according to the following formula (Table 1).

$\mathrm{X}=\mathrm{A} \times \mathrm{B}$

Where $\mathrm{X}$ is the number of excreted oocysts in total feces per day in each group, $\mathrm{A}$ is fecal OPG in each group, B is the total weight of feces in each group.

Table 1. The number of Eimeria oocysts excreted in the feces of broiler chickens experimentally infected with different doses of oocysts

\begin{tabular}{lccccc}
\hline Group & $\begin{array}{c}\text { The number of sporulated } \\
\text { oocysts administered to 14- } \\
\text { day-old broilers }\end{array}$ & $\begin{array}{c}\text { the number of } \\
\text { oocysts per } \\
\text { gram }\end{array}$ & $\begin{array}{c}\text { The number of } \\
\text { oocysts excreted in } \\
\text { total feces per day }\end{array}$ & $\begin{array}{c}\text { The dose of } \\
\text { infection (Log) }\end{array}$ & $\begin{array}{c}\text { The total number } \\
\text { of oocysts in the } \\
\text { feces (Log) }\end{array}$ \\
\hline 6 & 15 & 94 & 413882 & 1.17609126 & 5.61687654 \\
5 & 62 & 662 & 2868446 & 1.81954394 & 6.45764668 \\
4 & 125 & 1530 & 7068600 & 2.12385164 & 6.84933341 \\
3 & 250 & 1780 & 8659700 & 2.38560627 & 6.93750285 \\
2 & 1000 & 6880 & 28483200 & 3.06707086 & 7.45458877 \\
1 & 2000 & 4080 & 18535440 & 3.30124709 & 7.26800220 \\
\hline
\end{tabular}

\section{Growth performance analysis}

Broilers were individually weighed at the beginning ( 14 days old) and at the end of the experiment ( 21 days old). The average daily weight gain was calculated to determine the effect of the infectious dose on broiler productivity.

\section{Calibration curve}

The calibration curve was made to establish the dependence of the excretion rate of E. tenella oocysts on the infectious dose. For this, a linear regression analysis was performed between the logarithmic values of the number of inoculated oocysts and the total number of oocysts isolated in the feces. The following equation describes the calibration curve:

$$
\mathrm{Y}=\mathrm{A}+\mathrm{Bx}
$$

Where, $y$ is the log of the total number of oocysts in the feces, $\mathrm{x}$ is the $\log$ of the infection dose, $\mathrm{A}$ and $\mathrm{B}$ are the regression coefficients (Figure 1).

Figure 1. Calibration curve; the relationship between the infectious dose and the number of oocysts shed in the feces of broiler chickens. LOG: infection dosis and LOG oocysts excreted.

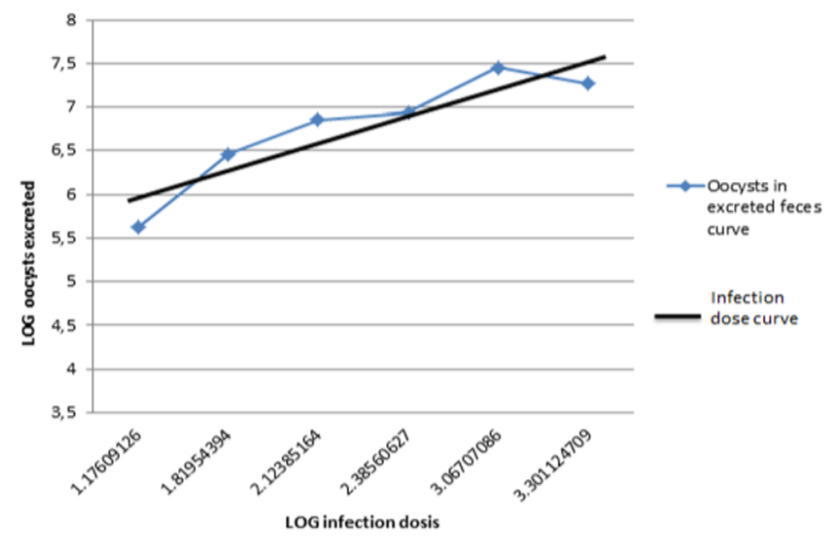

\section{Statistical analysis}

Experimental data on fecal OPG were subjected to statistical analysis using the method of Plokhinsky (1978). The $\mathrm{P}<0.05$ were considered statistically significant. SAS/Stat software, version 9 (SAS Institute Inc., USA) was used to analysis of data. Regression analysis was performed using the Excel program.

\section{RESULTS}

After the administration of different doses of sporulated oocysts, decreased activity, reduced food intake, lethargy and wings in a down position were observed in infected chickens. Apparently, this is a reaction to stress caused by catching, moving from one block to another, weighing, numbering and giving oocysts culture. No complications during the administration of E.tenella oocysts and after that were not observed. Broilers treated with pure cultures of sporulated oocysts and the control group did not differ from each other according to the data of general clinical observations. 
At the beginning of the experiment, the average live weight of broilers in groups 1,2,3,4,5, and 6 were 253.3, $241.7,245.7,243.2,255.8$ and $244.3 \mathrm{~g}$, respectively. The weight of the control group was $246.9 \mathrm{~g}$ on the first day of the experiment. The results of second weight measurement at seven days post-infection indicated noticeable changes at the weight of broilers infected with the sporulated oocysts. The average weight gain relative to the initial weight in the groups 1, 2 and 3, was 241.8, 244.5 and $270.9 \mathrm{~g}$, respectively. The average weight gain was more remarkable in broilers of groups 4, 5 and 6 and amounted to 356.3, 412.2 and $454.5 \mathrm{~g}$, respectively. In the control group, the average weight gain was $465.6 \mathrm{~g}$. In chickens of groups 1 to 3 , the infectious process proceeded more intensively and had a negative effect on the average daily weight gain. This was evidenced by the growth rate of the initial body weight. The higher levels of OPG were found in broilers of the groups 1 and 2 (Table 2). The body weight gain in groups 1 to 4 compared to the control group was significant $(\mathrm{P}<0.05)$. The weight gain in groups 5 and 6 did not differ statistically from the control group $(\mathrm{P}>0.05)$.

Table 2. The effect of different doses of E. tenella oocysts on weight gain in experimentally infected broiler chickens

\begin{tabular}{|c|c|c|c|c|c|c|}
\hline \multirow[b]{2}{*}{ Group } & \multirow[b]{2}{*}{$\begin{array}{c}\text { Infection dose } \\
\text { (oocysts/ml) }\end{array}$} & \multicolumn{2}{|c|}{ Average weight (g) } & \multirow[b]{2}{*}{$\begin{array}{l}\text { Weight } \\
\text { gain }(g)\end{array}$} & \multirow[b]{2}{*}{$\begin{array}{l}\text { The average daily } \\
\text { weight gain (g) }\end{array}$} & \multirow[b]{2}{*}{ p-value } \\
\hline & & $\begin{array}{c}\text { Initial weight } \\
\text { (before infection) }\end{array}$ & $\begin{array}{c}7 \text { days } \\
\text { post-infection }\end{array}$ & & & \\
\hline 1 & 2,000 & $253.3 \pm 8.86$ & $495.1 \pm 20.29$ & 241.8 & 34.5 & $\mathrm{P}<0.05$ \\
\hline 2 & 1,000 & $241.7 \pm 8.94$ & $486.2 \pm 20.42$ & 244.5 & 34.9 & $\mathrm{P}<0.05$ \\
\hline 3 & 250 & $245.5 \pm 9.57$ & $516.4 \pm 21.17$ & 270.9 & 38.7 & $\mathrm{P}<0.05$ \\
\hline 4 & 125 & $243.2 \pm 8.75$ & $599.6 \pm 23.98$ & 356.3 & 50.9 & $\mathrm{P}<0.05$ \\
\hline 5 & 62 & $255.8 \pm 8.95$ & $668.0 \pm 26.05$ & 412.2 & 58.8 & $\mathrm{P}<0.05$ \\
\hline 6 & 15 & $244.3 \pm 9.77$ & $698.8 \pm 27.95$ & 454.5 & 64.9 & $\mathrm{P}<0.05$ \\
\hline 7 & 0 & $246.9 \pm 8.88$ & $712.5 \pm 27.07$ & 465.6 & 66.5 & $\mathrm{P}<0.05$ \\
\hline
\end{tabular}

Two chickens (one from group 2 and the other from group 7) died during the experiment. These broilers were subjected to necropsy. At the autopsy of dead broiler from group 2, the following signs were found: mucous membranes and muscles were pale; the mucous membrane of the cecum was reddish with hemorrhage and necrosis as well as the serous membrane of the cecum was dark red. A large number of oocysts were found in mucosal scrapings of the cecum. The necropsy of the dead chick from the control group showed the absence of the aforementioned signs and the coccidian oocysts.

The fecal examinations showed the presence of E. tenella oocysts in experimental groups, but the number was different in groups. Broilers in the control group were free from infection at all times. In group 1, the average number of oocysts in one chamber was 20.4 over the entire study period and the average OPG was 4,080. The average number of oocysts in the one chamber during the study period was 34.4 in group 2 . The average OPG in group 2 was 6,880 , which was the highest record among infected broilers. It can be assumed that the sporulated oocysts in the broiler's intestine of group 2 had the highest survival rate. In chickens of the groups 3 and 4, the average number of oocysts in the one chamber during the study period was 8.9 and 7.65, respectively. The average OPG in groups 3 and 4 was 1,780 and 1,530 , respectively. Broilers of groups 5 and 6 did not have oocysts in the feces during six days post-infection. In group 5 , the average number of oocysts in the one chamber was 3.31 during the last 6 days of the study and the average OPG was 662 . While in the broilers of group 6 , the number of oocysts was insignificant, the average number of oocysts in the one chamber was 0.47 and the average OPG was 94 .

A certain cyclical nature was noticeable when analyzing quantitative indices of oocysts secretion in the droppings of experimentally infected chickens. Oocysts were absent or low over six days post-infection. While the number of detected oocysts increased during 7, 8 and 9 days post-infection. Oocysts in the feces were noticeably less after 10 days post-infection, but then the number increased significantly. Analysis of the results of experimental infection of broilers by E. tenella sporulated oocysts showed a linear relationship between the infectious dose and the number of oocysts shed in the feces.

\section{DISCUSSION}

Coccidiosis in broilers is the most common infection in free-range poultry farming in Russia (Vershinin, 1996). This disease causes significant economic loss. The high prevalence of Eimeria infection in many poultry farms in Russia is due to the residual contamination of the floor after disinfection and the poor quality of the drugs used, which do not provide high efficacy treatment of coccidian oocysts (Mishin and Kadnikova, 2011; Safiullin, 2019). The combined preparations are essential to inhibit developmental stages (endogenous and exogenous) of coccidia. Previous studies by the same authors conducted in the farms of Moscow, Belgorod and Voronezh regions indicated that the system adopted by the farms for preparing and disinfecting poultry houses using the recommended dose of caustic sodium did not provide complete disinfection from the infective elements of intestinal parasitic protozoa (Okolelova and Kashkovskaya, 2016: Safiullin et al., 2017; Kachanova and Safiullin, 2019). At different intensities of coccidiosis in broilers, it is 
necessary to use preparations that provide high efficiency against this infection (Kashkovskaya et al., 2019).

In the current study, the increase in body weight of broilers in groups 1 to 4 , was significantly lower compared to broilers of groups 5, 6 and $7(\mathrm{P}<0.05)$ during the 7-days observation period. The lowest average daily weight gain was found in broilers of groups 1, 2 and 3 and amounted to 34.5, 34.9 and $38.7 \mathrm{~g}$, respectively. The weight gain in broilers of group 4 was higher compared with the noted groups, but lower than the control group $(\mathrm{P}<0.05)$. The numbers of E.tenella oocysts per gram of faces ranged from 7.3 to 36.5 thousand specimens. In addition, the number of E.tenella oocysts per $\mathrm{g}$ of feces showed the need for timely adjustment of the anticoccidial program and the success of the activities. The obtained results established that the number of Eimeria oocytes more than 12 thousand per gram of faces have a negative effect on the weight gain of broiler chickens.

\section{CONCLUSION}

In all groups, Eimeria oocysts were detected from the sixth day after the inoculation, which indicated the success of infection. A quantitative analysis of the results showed that the number of Eimeria oocysts shed in feces of infected chickens periodically changed. The highest OPG was recorded at 7,8 and 9 days post-infection. Then the OPG decreased during 10 and 11 days post-infection and further, it increased again. Analysis of the research results demonstrated a linear relationship between the infectious dose and the number of oocysts isolated from the feces during the period of study.

\section{DECLARATIONS}

\section{Acknowledgments}

The authors express their gratitude to the staff of the company "CID LINE" for providing the culture of E. tenella for the experiment. Also, we would like to thank the Federal Scientific Center "All-Russian Research and Technological Poultry Institute" of RAS Sergeev Posad, Russia

\section{Authors' contribution}

Rinat T. Safiullin designed and performed the experiments as well as wrote the manuscript. Kachanova E. Olegovna and Elvira I. Chalysheva conducted the research, analyzed the results and participated in the manuscript writing. Oleg N. Andreyanov prepared E.tenella culture and examined broilers after infection. Finally, all authors read and approved the final manuscript.

\section{Competing interests}

The authors declared that do not have any conflict of interests.

\section{REFERENCES}

Akbaev MSh, Vodyanov AA and Kosminkov NI (2000). Parasitology and invasive animal diseases, Moscow, p. 743.

Awais MM (2012). Seasonal prevalence of coccidiosis in industrial broiler broilers in Faisalabad. Tropical Animal Health and Production, 44 (2): 323-328. DOI: http://dx.doi.org/10.1007/s11250-011-0024-x.

Bakulin VA (2006). Diseases of birds. Saint Petersburg, p. 689. Available at: http://webpticeprom.ru/ru/handbooks-veterinarydiseases.html?pageID=1375175522

Bondarenko LA, Safiullin RT and Novikov PV and (2013). Contamination of environmental objects by oocyst of Eimeria on poultry farms. Russian Parasitological Journal, 4: 46-53. Available at: https://www.vniigis.ru/izdaniya/rossiyskiy-parazitologicheskiyzhurnal/vipuski 2013/rossiyskiy-parazitologicheskiy-zhurnal-2013-vypusk-4-kvartala/46-53-kontaminatsiya-obektov-vneshneysredy-ootsistami-eymeriy-na-ptitsefabrikakh-bondarenko-l-a-mur/

Cha JO, Zhao J, Yang MS, Kim WI, Cho HS, Lim CW and Kim B (2018). Oocyst-shedding patterns of three Eimeria species in broilers and shedding pattern variation depending on the storage period of Eimeria tenella oocysts. Journal of Parasitology, 104 (1): 18-23. DOI: http://dx.doi.org/10.1645/16-132.

Fisinin VI (2008). Trends in the integration development of poultry in Russia. Poultry and poultry products 2: 17-21.

Fisinin VI, Egorov IL and Draganov IF (2011). Feeding poultry, Moscow, p.344. Available at: https://www.rulit.me/books/kormlenieselskohozyajstvennoj-pticy-read-454484-1.html

Habriev RU (2005). The guidance to experimental (preclinical) studying of new pharmacological substances, Moscow, p. 832.

Kachanova EO and Safiullin RT (2018). Distribution of Eimeria invasion in broilers and repairing young hens of egg and meat-egg breed. Collection of scientific articles adapted from the International scientific conference "Theory and practice of parasitic disease control”, 80 (2): 177-182.

Kachanova EO and Safiullin RT (2019). Guidelines for a comprehensive program to control the endogenous and exogenous stages of Eimeria oocysts in broiler chickens with floor keeping technology in industrial production, Moscow, p.36.

Kashkovskaya LM, Balyshev AV, Abramov VE and Zubarev VN (2019). Modern approach to the fight against eimeriosis of broiler chickens. Veterinary Medicine, 3: 31-33. DOI: http://dx.doi.org/10.30896/0042-4846.2019.22.3.31-34 
Kirillov AI (2008). Coccidiosis of birds, Moscow, p. 230.

Krylov MV (1996). The determinant of parasitic protozoa, St. Petersburg, p. 602.

Mishin VS and Kadnikova GF (2011). Coccidiosis of chickens. Means and methods of solving the problem. Farm Animal Veterinary Journal, 3:16-17

Murzakov RR and Safiullin RT (2012). Methodical provisions on the fight against broilers eimeriosis at different technologies of their rearing in the central zone of Russia, Moscow, pp. 24.

Okolelova TM and Kashkovskaya LM (2016). The effectiveness of the drug Strolitin in Russian and Brazilian broiler growing conditions. Poultry farming: Scientific and Production Journal, 3: 24-26. Available at: https://elibrary.ru/item.asp?id=25919768

Plokhinsky NA (1978). Mathematical methods in biology. Publishing House of Moscow State University, Moscow, p. 264.

Available at: https://www.libex.ru/detail/book512589.html

Prakashbabu BCh, Thenmozhi V, Limon G, Kundu K, Kumar S, Garg R, Clark EL, Srinivasa Rao ASR, Raj DG, Raman M et al. (2017). Eimeria species occurrence varies between geographic regions and poultry production systems and may influence parasite genetic diversity. Veterinary parasitology, 233: 62-72. DOI: https://doi.org/10.1016/j.vetpar.2016.12.003

Rules for conducting disinfection of state veterinary supervision objects (2002), Moscow, p. 73.

Safiullin RT (2019). Parasitic diseases of birds, means and methods of control, Moscow, p. 260.

Safiullin RT and Murzakov RR (2012). Epizootic situation on Eimeria in broilers with different technologies of their cultivation in the conditions of the Moscow region. Sat scientific conf. "Theory and practice of combating parasitic diseases", 13: 256 - 260. Available at: https://www.vniigis.ru/1_dlya_failov/TPB/Vniigis_2012_konferenciya.pdf

Safiullin RT, Shibitov SK, Yablonskii SA and Oleinikova VP (2016). The efficacy of a complex preparation Delegol against oocysts Eimeria birds. Veterinary Journal, 2(2): 115-119.

Safiullin RT, Titova TG and Nurtdinova TA (2017). A comprehensive program against bird coccidiosis to reduce the circulation of resistant forms of Eimeria at the poultry site. Russian Parasitological Journal, 3: 288-298.

Vershinin II (1996). Coccidiosis of animals and their differential diagnosis, Ekaterinburg, p. 264 